\title{
Chronic hypertension with related drug treatment of pregnant women and congenital abnormalities in their offspring: a population-based study
}

\begin{abstract}
Ferenc Bánhidy ${ }^{1}$, Nándor Ács ${ }^{1}$, Erzsébet $\mathrm{H}_{\text {Puhó }^{2}}$ and Andrew E Czeizel ${ }^{2}$
Chronic hypertension (CH) is a common chronic disease and occurs frequently in pregnant women. The teratogenic/fetotoxic effect of certain antihypertensive drugs has been shown. The objective of this study was to investigate the association between pregnant women with $\mathrm{CH}$ and the possible risk of congenital abnormalities (CAs) among their offspring. The prevalence of medically recorded $\mathrm{CH}$ in the prenatal maternity logbook was compared between 1030 pregnant women who later had offspring with $\mathrm{CA}$ (case group) and 1579 pregnant women with $\mathrm{CH}$ who later delivered newborn infants without CA (control group). Control newborn infants were matched to cases in the population-based data set of the Hungarian Case-Control Surveillance System of Congenital Abnormalities during 1980-1996. Of 23 different CA groups with informative offspring, esophageal atresia/stenosis was a greater risk in pregnant women with $\mathrm{CH}$ (adjusted odds ratios with $95 \%$ confidence intervals: 3.1 , 1.4-6.8). In conclusion, a higher risk of esophageal atresia/stenosis was found in the offspring of pregnant women with severe $\mathrm{CH}$, which could not be explained by related drug treatments. This finding requires confirmation or lack thereof by future studies. Hypertension Research (2011) 34, 257-263; doi:10.1038/hr.2010.227; published online 25 November 2010
\end{abstract}

Keywords: chronic hypertension; congenital abnormalities; esophageal atresia/stenosis; pregnancy; related drug treatment

\section{INTRODUCTION}

Hypertension is one of the most common chronic conditions and is harmful for the structure and function of the heart and arteries. Hypertension can also accelerate the development of arteriosclerosis.

The distribution of blood pressure in the population is continuous, thus there is no obvious natural threshold between normal and pathological blood pressure such as exists for the so-called qualitative (yes or no) diseases. ${ }^{1}$ Hypertension is frequently neglected, partly for this reason and partly because of the lack of obvious symptoms in the early phase of the disease. ${ }^{2}$ According to the consensus of experts based on several studies, there is a well-known definition of hypertension, namely, blood pressure of $140 / 90 \mathrm{~mm} \mathrm{Hg}$ or more for adults age 18 years or older, as measured by the recommended criteria. ${ }^{3}$ According to the classification of hypertension by severity, Stage 1 (140-159/90$99 \mathrm{~mm} \mathrm{Hg})$ and Stage $2(\geqslant 160 / 100 \mathrm{~mm} \mathrm{Hg})$ have been differentiated. ${ }^{1}$

Another classification of hypertension is based on its origin. ${ }^{1}$ Primary or essential hypertension occurs in about $95 \%$ of patients due to the interaction of polygenic liability and hazardous environmental factors, whereas secondary hypertension is caused by definable causes, such as chronic kidney disease, renal artery stenosis, coarctation of the aorta and Cushing's disease. ${ }^{2}$

Hypertension can be present before and during pregnancy in 1-5\% of women. ${ }^{4}$ A classification system of hypertension in pregnant women prepared by the National Institutes of Health (NIH), differentiated four categories: chronic hypertension $(\mathrm{CH})$, pre-eclampsiaeclampsia, pre-eclampsia superimposed upon $\mathrm{CH}$ and gestational hypertension. ${ }^{5} \mathrm{CH}$ in pregnant women is defined as hypertension that is present and observable before pregnancy or that is diagnosed before the 20th week of gestation. Special guidelines were performed for the care of pregnant women with hypertension and the possible teratogenic and/or fetotoxic effects of antihypertensive drugs. ${ }^{4-11}$ However, as our previous study showed, the efficacy of antihypertensive treatment in pregnant women is not good because they have a higher risk for some pregnancy complications and adverse birth outcomes, such as low birth weight newborns. ${ }^{12}$

The objective of our study was to evaluate the possible association of maternal $\mathrm{CH}$ and related drug treatments in pregnant women with the risk of structural birth defects, that is, congenital abnormalities (CAs) in their offspring, from among the population-based data set of the Hungarian Case-Control Surveillance of Congenital Abnormalities (HCCSCA $).{ }^{13}$

\section{METHODS}

Study subjects

Cases affected with CAs were selected from the data set of the Hungarian Congenital Abnormality Registry (HCAR), $1980-1996^{14}$ for the HCCSCA data

${ }^{1}$ From the Second Department of Obstetrics and Gynecology, Semmelweis University, School of Medicine, Budapest, Hungary and ${ }^{2}$ Foundation for the Community Control of Hereditary Diseases, Budapest, Hungary

Correspondence: Dr AE Czeizel, Foundation for the Community Control of Hereditary Diseases, Budapest 1026, Törökvész lejtö 32, Hungary.

E-mail: czeizel@interware.hu

Received 25 March 2010; revised 21 July 2010; accepted 23 August 2010; published online 25 November 2010 
set. Notification to the HCAR of cases with CA is mandatory for physicians from the birth of cases until the end of the first postnatal year. Most cases are reported by obstetricians and pediatricians. In Hungary, almost all deliveries take place in inpatient obstetric clinics, and the birth attendants are obstetricians. Pediatricians work in the neonatal units of inpatient obstetric clinics or in various inpatient and outpatient pediatric clinics. Autopsy was mandatory for all infant deaths and common (about 80\%) among stillborn fetuses during the study period. Pathologists sent a copy of the autopsy report to the HCAR if defects were identified among stillbirths and infant deaths. Since 1984, fetal defects diagnosed in prenatal diagnostic centers with or without termination of pregnancy have also been included in the HCAR.

CAs were divided into three groups: lethal (if defects cause stillbirths or infant deaths or if pregnancies were terminated due to fetal defects in more than $50 \%$ of cases), severe (CAs cause handicap or death without medical intervention) and mild (CAs require medical intervention but life expectancy is good). Both lethal and severe CAs constitute major CAs. (Minor anomalies or morphological variants without serious medical as well as cosmetic consequences are excluded from the CA class.) In addition, two main categories of cases with CAs were differentiated: isolated (only one organ is affected) and multiple (concurrence of two or more CAs in the same person affecting at least two different organ systems).

The total (birth+fetal) prevalence of cases with CAs diagnosed from the second trimester of pregnancy through the age of 1 year was 35 per 1000 informative offspring (live-born infants, stillborn fetuses and electively terminated malformed fetuses) in the HCAR during 1980-1996. ${ }^{14}$ However, about $90 \%$ of major CAs were recorded in the HCAR during the 17 years of the study period. ${ }^{15}$

There were three criteria for the selection of cases with CAs from the HCAR for the HCCSCA data set. (i) Cases reported after 3 months of birth or pregnancy termination were excluded (77\% of cases were reported during the first 3-month time window and the rest included mainly mild CAs); (ii) three mild CAs (congenital dysplasia of hip and inguinal hernia, large hemangioma); and (iii) CA syndromes caused by major mutant genes or chromosomal aberrations with pre-conceptional origin were also excluded.

Controls were defined as newborn infants without CAs, and they were selected from the National Birth Registry of the Central Statistical Office for the HCCSCA. In general, two controls were matched to every case according to sex, birth week and district of parents' residence.

\section{Collection of exposure data}

Three sources of data were evaluated.

\section{(1) Prospective medically recorded data}

Mothers were asked in an explanatory letter to send their prenatal maternity logbook and other medical records, particularly discharge summaries of their deliveries, including their diseases during the study pregnancy and their child's CA to the HCCSCA. These medical documents were sent back after evaluation to the mothers. Prenatal care was mandatory for pregnant women in Hungary (if a woman did not visit the prenatal care clinic, she did not receive a maternity grant and leave); therefore, nearly $100 \%$ of pregnant women visited prenatal care clinics, on average seven times during their pregnancies. The first visit was between the 6th and 12th gestational week. The blood pressure of pregnant women is measured during each visit to the prenatal care clinic. The task of obstetricians is to record all pregnancy complications, maternal diseases (for example, $\mathrm{CH}$ ) and related drug prescriptions in the prenatal maternity logbook.

\section{(2) Retrospective self-reported maternal information}

A structured questionnaire with a list of medicinal products (drugs and pregnancy supplements) and diseases, as well as a printed informed consent form, were mailed to the mothers immediately after the selection of cases and controls. The questionnaire requested information on pregnancy complications and maternal diseases, on medicinal products taken during pregnancy according to gestational months and on family history of CAs. To standardize the answers, mothers were asked to read the enclosed lists of medicinal products and diseases (for example, hypertension) as a memory aid before filling in the questionnaire.
The mean \pm s.d. time elapsed between the birth or pregnancy termination and the return of the 'information package' (questionnaire, logbook, discharge summary and informed consent form) in our prepaid envelope was $3.5 \pm 1.2$ and $5.2 \pm 2.9$ months in the case and control groups, respectively.

\section{(3) Supplementary data collection}

Regional nurses were asked to visit all non-respondent case mothers at home and helped them to fill in the same questionnaire. Regional nurses also evaluated the available medical records and obtained data regarding smoking and drinking habits through a cross-interview of mothers and their close relatives, if living in the same household. The so-called family consensus was recorded. Smoking habits were evaluated with regard to the number of cigarettes per day, whereas three groups of drinking habits were differentiated: (i) abstinent or occasional drinkers (less than one drink per week), (ii) regular drinkers (from one drink per week to one drink daily) and (iii) hard drinkers (more than one drink per day). Regional nurses visited only 200 nonrespondent and 600 respondent control mothers in two validation studies, ${ }^{16,17}$ using the same method as used for the case mothers, because the ethics committee considered this follow-up to be disturbing for the parents of healthy children.

Overall, 17 years of data collected by the HCCSCA between 1980 and 1996 were evaluated. This period ended at 1996 because the data collection method changed in 1997 (all mothers were visited by regional nurses). The recently collected data had not been validated at the time of the analysis.

Thus, we were able to evaluate 22843 malformed newborns or fetuses ('informative offspring') in the case group, $96.3 \%$ of the total case group ( $84.4 \%$ from those who replied to the mailing and $11.9 \%$ who were observed during nurse visits). The group of controls included 38151 newborns infants without CAs, $83.0 \%$ of the total control group $(80.9 \%$ from among respondents, $2.1 \%$ from home visits). Informed consent was provided by $98 \%$ of the mothers, the names and addresses were deleted for the other $2 \%$.

The details of the methodology of the HCAR and HCCSCA, as well as the aims and strategies utilized by these organizations, were published in previous papers. ${ }^{13-15}$

The diagnosis of pregnant women studied, corresponded to $\mathrm{CH}$ because pregnant women with pre-eclampsia-eclampsia, pre-eclampsia superimposed upon $\mathrm{CH}$ and gestational hypertension were excluded from the study. In addition, pregnant women with secondary hypertension due to different primary causes were also excluded from the study. Therefore, $\mathrm{CH}$ corresponded to the essential hypertension among the pregnant women interviewed.

Hungarian medical doctors follow the international recommendations at the diagnosis of hypertension, but $\mathrm{CH}$ diagnosis was differentiated according to the source of information: (i) prospectively and medically recorded $\mathrm{CH}$ in the prenatal maternity logbook and (ii) $\mathrm{CH}$ based only on retrospective maternal information. $\mathrm{CH}$ recorded by obstetricians in the prenatal maternity logbook was based on the available medical documents and blood pressure measurements obtained at the prenatal care clinics visited by the pregnant women. We decided to evaluate these patients with prospectively and medically recorded $\mathrm{CH}$ because if the diagnosis of $\mathrm{CH}$ was based only on maternal information, in general, the systolic/diastolic values were not mentioned and the differential diagnosis among different hypertension forms was not valid, rendering the diagnosis of $\mathrm{CH}$ questionable.

The $\mathrm{CH}$-related drug treatments were also evaluated. Other potential confounding factors included maternal age, birth order, marital and employment status as indicators of socio-economic status (because they showed a good correlation with the level of education and income), ${ }^{18}$ other maternal diseases and pregnancy supplements (particularly folic acid and multivitamins as indicators of the standard of pre-conceptional and prenatal care). However, the use of folic acid and folic acid-containing multivitamins are also important for the prevention of some CAs. ${ }^{19}$ Gestational age was calculated from the first day of the last menstrual period.

\section{Statistical methods}

We used SAS version 8.02 (SAS Institute Inc., Cary, NC, USA) for statistical analyses. Contingency tables were prepared for the main study variables. First, the characteristics of mothers with $\mathrm{CH}$ were compared with those of all 
mothers without $\mathrm{CH}$. The chi-square test was used for categorical variables, whereas Student's $t$-test was used for quantitative variables. Second, other maternal diseases and hypertension-related drug treatments were evaluated by ordinary logistic regression models, and odds ratios with their $95 \%$ confidence intervals were calculated. Finally, we compared the prevalence of $\mathrm{CH}$ during pregnancy studied of the mothers who had later offspring affected with specified CA groups (including at least three cases), with the prevalence of $\mathrm{CH}$ in the mothers of matched control pairs without CA. Adjusted odds ratios with $95 \%$ confidence intervals were evaluated in conditional logistic regression models for the occurrence of $\mathrm{CH}$. We examined confounding variables by comparing the odds ratios for $\mathrm{CH}$ in the models with and without inclusion of the potential confounding variables. Finally, maternal age $(<20$ years, 20-29 years, and 30 years or more), birth order (first delivery or one or more previous deliveries), employment status, antihypertensive-drug treatments (yes/no) and folic acid use (yes/no) were included in the models as potential confounders.

\section{RESULTS}

Of 22843 case mothers, 1030 (4.5\%) had medically recorded $\mathrm{CH}$. The total number of births in Hungary was 2146574 during the study period. Therefore, the 38151 controls represented $1.8 \%$ of all Hungarian births. Of the 38151 control mothers, 1597 (4.1\%) had medically recorded $\mathrm{CH}$.

Of the 1030 case mothers with $\mathrm{CH}, 37$ (3.6\%) were not treated because of their $\mathrm{CH}$; among the 1579 control mothers with $\mathrm{CH}, 57$ $(3.6 \%)$ were not treated because of their $\mathrm{CH}$. Originally, we wanted to differentiate between treated and untreated mothers with $\mathrm{CH}$; however, we ultimately evaluated these two subgroups together because of the low number of untreated mothers with $\mathrm{CH}$.
The main variables for mothers with $\mathrm{CH}$ as compared with mothers without $\mathrm{CH}$ as a reference sample are shown in Table 1. This comparison indicates a higher mean maternal age due to the larger proportion of women over 30 years among mothers with $\mathrm{CH}$. The proportion of professional, managerial and skilled working women was somewhat larger among mothers with $\mathrm{CH}$. Folic acid and multivitamins were used more frequently during pregnancy by mothers with $\mathrm{CH}$, particularly among control mothers, as compared with mothers without $\mathrm{CH}$. The comparison of case and control mothers with $\mathrm{CH}$ showed some difference with regard to mean birth order, proportion of unmarried women, employment status and folic acid supplementation.

Of the 2718 case mothers visited at home, 2640 could be evaluated. Among those evaluated, 118 (4.5\%) had $\mathrm{CH}$. Of these 118 women, 35 (29.7\%) smoked during the study pregnancy; among the 2,522 mothers without $\mathrm{CH}, 545(21.6 \%)$ smoked. Of the 800 control mothers visited at home, $36(4.5 \%)$ were affected with $\mathrm{CH}$ and 8 (22.2\%) smoked during the study pregnancy; this figure was $18.5 \%$ among the 764 mothers without $\mathrm{CH}$. The proportion of regular and hard drinkers was not significantly different among the study groups.

The occurrence of acute maternal diseases (for example, influenza) did not differ among the study groups. Among chronic diseases, migraine (4.4 vs. $2.0 \%)$ and cardiac dysrhythmias (4.3 vs. $0.2 \%)$ occurred more frequently in mothers with $\mathrm{CH}$ than in the reference sample. However, there was no difference in the rate of other maternal diseases, for example, hyperthyroidism, between case mothers $(N=17$; $1.7 \%)$ and control mothers $(N=24 ; 1.5 \%)$ with $\mathrm{CH}$.

Table 1 Maternal variables of pregnant women with $\mathrm{CH}$

\begin{tabular}{|c|c|c|c|c|c|c|c|c|c|}
\hline \multirow[b]{3}{*}{ Variables } & \multicolumn{4}{|c|}{ Case mothers } & \multicolumn{4}{|c|}{ Control mothers } & \multirow{3}{*}{$\begin{array}{l}\text { Comparison between case } \\
\text { and control mothers with } \mathrm{CH}\end{array}$} \\
\hline & \multicolumn{2}{|c|}{ Without $\mathrm{CH}(\mathrm{N}=21813)$} & \multicolumn{2}{|c|}{ With $\mathrm{CH}(\mathrm{N}=1030)$} & \multicolumn{2}{|c|}{ Without $\mathrm{CH}(\mathrm{N}=36572)$} & \multicolumn{2}{|c|}{ With $\mathrm{CH}(\mathrm{N}=1579)$} & \\
\hline & No. & $\%$ & No. & $\%$ & No. & $\%$ & No. & $\%$ & \\
\hline \multicolumn{10}{|l|}{ Quantitative } \\
\hline \multicolumn{10}{|l|}{ Maternal age, years } \\
\hline 19 or less & 2426 & 11.1 & 80 & 7.8 & 3170 & 8.7 & 107 & 6.8 & \\
\hline $20-29$ & 14924 & 68.4 & 669 & 65.0 & 26514 & 72.5 & 1088 & 68.9 & $\chi_{2}{ }^{2}=4.4, P=0.11$ \\
\hline 30 or more & 4463 & 20.5 & 281 & 27.3 & 6888 & 18.8 & 384 & 24.3 & \\
\hline Mean, s.d. & 25.4 & 5.2 & 26.5 & 5.7 & 25.4 & 4.9 & 26.1 & 5.4 & $t=1.8, P=0.07$ \\
\hline \multicolumn{10}{|l|}{ Birth order } \\
\hline 1 & 10191 & 46.7 & 517 & 50.2 & 17404 & 47.6 & 805 & 51.0 & $\chi_{1}^{2}=0.2, P=0.69$ \\
\hline 2 or more & 11622 & 53.3 & 513 & 49.8 & 19168 & 52.4 & 774 & 49.0 & \\
\hline Mean, s.d. & 1.9 & 1.1 & 1.8 & 1.1 & 1.7 & 0.9 & 1.7 & 0.9 & $t=2.5, P=0.01$ \\
\hline \multicolumn{10}{|l|}{ Categorical } \\
\hline Unmarried & 1213 & 5.6 & 56 & 5.4 & 1417 & 3.9 & 54 & 3.4 & $\chi_{1}^{2}=6.3, P=0.01$ \\
\hline \multicolumn{10}{|l|}{ Employment status } \\
\hline Professional & 1783 & 8.2 & 118 & 11.5 & 4165 & 11.4 & 188 & 11.9 & \\
\hline Managerial & 4712 & 21.6 & 256 & 24.9 & 9699 & 26.5 & 435 & 27.6 & \\
\hline Skilled worker & 6017 & 27.6 & 312 & 30.3 & 11157 & 30.5 & 533 & 33.8 & $\chi_{6}{ }^{2}=15.4, P=0.02$ \\
\hline Semi-skilled worker & 3711 & 17.0 & 158 & 15.3 & 5568 & 15.2 & 215 & 13.6 & \\
\hline Unskilled worker & 1452 & 6.7 & 51 & 5.0 & 1802 & 4.9 & 57 & 3.6 & \\
\hline Housewife & 2092 & 9.6 & 36 & 3.5 & 1995 & 5.5 & 43 & 2.7 & \\
\hline Others & 2046 & 9.4 & 99 & 9.6 & 2186 & 6.0 & 108 & 6.8 & \\
\hline Pregnancy supplements & & & & & & & & OR & $95 \% \mathrm{Cl}$ \\
\hline Folic acid & 10725 & 49.2 & 554 & 53.8 & 19807 & 54.2 & 968 & 61.3 & $0.7(0.6-0.9)$ \\
\hline Multivitamin & 1211 & 5.8 & 63 & 6.1 & 2279 & 6.5 & 123 & 7.8 & $0.8(0.6-1.1)$ \\
\hline
\end{tabular}

Abbreviations: $\mathrm{CH}$, chronic hypertension; $\mathrm{Cl}$, confidence intervals; $\mathrm{OR}$, odds ratios 
Table $2 \mathrm{CH}$-related drug treatments

\begin{tabular}{|c|c|c|c|c|c|c|c|c|c|c|}
\hline & \multicolumn{4}{|c|}{ Case mothers } & \multicolumn{4}{|c|}{ Control mothers } & & \\
\hline & \multicolumn{2}{|c|}{$\begin{array}{l}\text { Without } \mathrm{CH} \\
(\mathrm{N}=21813)\end{array}$} & \multicolumn{2}{|c|}{$\begin{array}{l}\text { With } \mathrm{CH} \\
(\mathrm{N}=1030)\end{array}$} & \multicolumn{2}{|c|}{$\begin{array}{l}\text { Without } \mathrm{CH} \\
(\mathrm{N}=36572)\end{array}$} & \multicolumn{2}{|c|}{$\begin{array}{l}\text { With } \mathrm{CH} \\
(\mathrm{N}=1579)\end{array}$} & \multicolumn{2}{|c|}{$\begin{array}{l}\text { Comparison between case } \\
\text { and control mothers with } \mathrm{CH}\end{array}$} \\
\hline & No. & $\%$ & No. & $\%$ & No. & $\%$ & No. & $\%$ & $O R$ & $95 \% \mathrm{Cl}$ \\
\hline \multicolumn{11}{|l|}{ Beta-receptor blockers } \\
\hline Pindolol & 39 & 0.2 & 53 & 5.1 & 57 & 0.2 & 85 & 5.4 & 1.0 & $0.7-1.3$ \\
\hline Propranolol & 39 & 0.2 & 53 & 5.1 & 57 & 0.2 & 85 & 5.4 & 1.0 & $0.7-1.3$ \\
\hline Ritodrine & 0 & 0.0 & 23 & 2.2 & 0 & 0.0 & 42 & 2.7 & 0.8 & $0.5-1.4$ \\
\hline Calcium receptor agonists & 17 & 0.1 & 20 & 1.9 & 0 & 0.0 & 33 & 2.1 & 0.9 & $0.5-1.6$ \\
\hline Fendiline & 0 & 0.0 & 46 & 4.5 & 0 & 0.0 & 66 & 4.2 & 1.1 & $0.7-1.6$ \\
\hline Captopril & 0 & 0.0 & 2 & 0.2 & 0 & 0.0 & 8 & 0.5 & 0.4 & $0.1-1.8$ \\
\hline Chlortalidone & 29 & 0.1 & 2 & 0.2 & 49 & 0.1 & 7 & 0.4 & 0.4 & $0.1-2.1$ \\
\hline Clopamide & 333 & 1.5 & 28 & 2.7 & 655 & 1.8 & 36 & 2.3 & 1.2 & $0.7-2.0$ \\
\hline Dihydralazine & 41 & 0.2 & 49 & 4.8 & 93 & 0.3 & 80 & 5.1 & 0.9 & $0.7-1.3$ \\
\hline Fenoterol & 181 & 0.8 & 147 & 14.3 & 183 & 0.5 & 218 & 13.8 & 1.0 & $0.8-1.3$ \\
\hline Methyldopa & 116 & 0.5 & 143 & 13.9 & 197 & 0.5 & 219 & 13.9 & 1.0 & $0.8-1.2$ \\
\hline Niacin+drotaverine $\mathrm{a}^{\mathrm{a}}$ & 8 & 0.0 & 4 & 0.4 & 18 & 0.0 & 6 & 0.4 & 1.0 & $0.3-3.6$ \\
\hline Potassium+magnesium ${ }^{b}$ & 660 & 3.0 & 112 & 10.9 & 1245 & 3.4 & 160 & 10.1 & 1.1 & $0.8-1.4$ \\
\hline Prazosine & 0 & 0.0 & 13 & 1.3 & 0 & 0.0 & 7 & 0.4 & 2.9 & $1.1-7.2$ \\
\hline Reserpine & 0 & 0.0 & 13 & 1.3 & 0 & 0.0 & 19 & 1.2 & 1.0 & $0.5-2.1$ \\
\hline Terbutaline & 1965 & 9.0 & 385 & 37.4 & 3384 & 9.3 & 610 & 38.6 & 0.9 & $0.8-1.1$ \\
\hline
\end{tabular}

Abbreviations: $\mathrm{CH}$, chronic hypertension; $\mathrm{Cl}$, confidence intervals; $\mathrm{OR}$, odds ratios. apapaverin.

bPanangin.

The frequency of drug treatment for $\mathrm{CH}$ is shown in Table 2. In decreasing order of frequency, the drugs used were as follows: terbutaline, verapamil, metoprolol, fenoterol, methyldopa and nifedipine (among case mothers). The only difference for control mothers was swapping of the 4th and 5th positions of fenoterol and methyldopa. Two cases and eight control mothers were treated with captopril, respectively. The comparison of case and control mothers with $\mathrm{CH}$ showed more frequent use of oxprenolol and prazosine, but less frequent use of metoprolol by case mothers with $\mathrm{CH}$. The use of some antihypertensive drugs was discontinued after the diagnosis of pregnancy.

The aim of this study was the evaluation of the possible association of case mothers with $\mathrm{CH}$, and the risk of different CAs among informative offspring. $\mathrm{CH}$ exposure started before conception and continued during the study pregnancy; therefore, different gestational months were not separated. On estimation of possible higher risk for CAs (that is, adjusted odds ratios), the occurrence of $\mathrm{CH}$ during pregnancy was compared between cases with different CAs and all matched controls (Table 3). There was a borderline-significant increase in the risk of total CAs, explained mainly by three CA groups-esophageal atresia/stenosis, multiple CAs and cardiovascular $\mathrm{CA}$ - in the offspring of case mothers with $\mathrm{CH}$.

There was a borderline risk of cardiovascular CA among the cases studied, but the observed rates of different cardiovascular CA types among 225 cases did not reveal significant differences from the expected rates, based on the total number of cardiovascular CA in the HCCSCA.

Two cases with multiple CAs had mothers who underwent captopril treatment and these newborns infants were born on 39th gestational week with birth weights of 2300 and $2500 \mathrm{~g}$, respectively. One boy was affected with pectus excavatum and generalized contractures of lower limb joints. This baby was born to a mother treated first with oxprenolol, methyldopa, chlortalidone and nifedipine, and with captopril from the 4th month until the end of the pregnancy. Another girl was affected with bilateral varus deformities of the feet (talipes equinovarus, deformation type), congenital dislocation of the hip and skull deformity; her mother was treated with methyldopa in the early pregnancy and captopril from the 5th month until the end of pregnancy (This pregnant woman was hospitalized at the end of pregnancy because of renal complications.). These two cases with multiple malformations exhibited the oligohydramnios sequence due to primary kidney lesion (though renal dysgenesis was not reported), with secondary postural deformities and intrauterine growth retardation. The so-called postural deformity association, including hip dysplasia-clubfoot and clubfoot-torticollis, occurred in two other cases with low birth weight (2100 and $2300 \mathrm{~g}$ ); their mothers were treated with prazosine. The component CAs of other multimalformed cases did not show a characteristic pattern, that is, 'syndrome.' However, the higher risk of multiple CAs disappeared when the four cases described above were removed from the analysis. 


\begin{tabular}{|c|c|c|c|c|c|}
\hline \multirow{2}{*}{ Study groups } & \multirow{2}{*}{ Total no. } & \multicolumn{4}{|c|}{ Pregnant women with $\mathrm{CH}$} \\
\hline & & No. & $\%$ & Crude & Adjusted $^{\mathrm{a}}$ \\
\hline Controls & 38151 & 1579 & 4.1 & Reference & Reference \\
\hline \multicolumn{6}{|l|}{ Isolated Cas } \\
\hline Microcephaly, primary & 111 & 3 & 2.7 & $0.9(0.2-3.7)$ & $1.2(0.3-5.1)$ \\
\hline Ear Cas & 354 & 13 & 3.7 & $0.9(0.4-1.8)$ & $0.9(0.5-1.9)$ \\
\hline Cleft lip \pm palate & 1375 & 50 & 3.6 & $1.1(0.7-1.6)$ & $1.1(0.8-1.6)$ \\
\hline Cleft palate & 601 & 32 & 5.3 & $1.4(0.9-2.4)$ & $1.5(0.9-2.5)$ \\
\hline Cardiovascular CAs & 4480 & 225 & 5.0 & $1.2(0.9-1.4)$ & $1.3(1.0-1.5)$ \\
\hline Esophageal atresia/stenosis & 217 & 21 & 9.7 & $2.8(1.3-5.9)$ & $3.1(1.4-6.8)$ \\
\hline Obstructive CAs of urinary tract & 343 & 22 & 6.4 & $1.0(0.5-1.9)$ & $1.0(0.5-1.9)$ \\
\hline Hypospadias (without coronal) & 3038 & 132 & 4.3 & $0.9(0.8-1.2)$ & $0.9(0.8-1.2)$ \\
\hline Undescended testis (after 3rd postnatal month) & 2052 & 77 & 3.8 & $0.8(0.6-1.1)$ & $0.8(0.6-1.1)$ \\
\hline Clubfoot & 2424 & 103 & 4.2 & $1.2(0.9-1.5)$ & $1.2(0.9-1.6)$ \\
\hline Poly/syndactyly & 1744 & 78 & 4.5 & $1.0(0.8-1.4)$ & $1.0(0.8-1.4)$ \\
\hline Limb deficiencies & 548 & 21 & 3.8 & $1.3(0.7-2.2)$ & $1.4(0.8-2.4)$ \\
\hline CAs of musculo-skeletal system & 585 & 24 & 4.1 & $0.8(0.5-1.3)$ & $0.8(0.5-1.3)$ \\
\hline Exomphalos/gastroschisis & 255 & 3 & 1.2 & $0.3(0.1-0.9)$ & $0.3(0.1-1.1)$ \\
\hline CA of diaphragm & 244 & 10 & 4.8 & $0.8(0.4-1.8)$ & $0.8(0.4-1.9)$ \\
\hline Other isolated CAs & 959 & 41 & 4.3 & $1.2(0.8-1.8)$ & $1.4(0.9-2.0)$ \\
\hline Multiple CAs & 1349 & 77 & 5.7 & $1.6(1.1-2.2)$ & $1.6(1.1-2.2)$ \\
\hline Total & 22843 & 1030 & 4.5 & $1.1(1.0-1.2)$ & $1.1(1.0-1.2)$ \\
\hline
\end{tabular}

Abbreviations: CAs, congenital abnormalities; $\mathrm{CH}$, chronic hypertension; $\mathrm{Cl}$, confidence intervals; OR, odds ratios.

Bold numbers indicate significant association.

aAjusted for maternal age, birth order, maternal employment status, related drug treatments and the use of folic acid during pregnancy.

Of the 21 cases with isolated esophageal atresia/stenosis, 11 had tracheo-esophageal fistulae; 3 were not affected with this associated CA, whereas the other 7 cases were unspecified. This three-fold increase in the risk of this CA among pregnant women with $\mathrm{CH}$ is noteworthy. All cases affected with esophageal atresia/stenosis were submitted to surgical intervention; of 21 cases, 20 survived.

\section{DISCUSSION}

The possible association between $\mathrm{CH}$ in mothers and CAs in their offspring was studied. A higher risk of esophageal atresia/stenosis was found among the offspring of pregnant women with $\mathrm{CH}$. The higher risk of multiple CAs among the children of pregnant women with $\mathrm{CH}$ can be explained by the captopril and prazosine treatment. Cardiovascular CAs have heterogeneous manifestations and origins; there was no higher risk for any specific type of cardiovascular CA, amidst the overall borderline risk of cardiovascular CAs among children of mothers with $\mathrm{CH}$.

The prevalence of $\mathrm{CH}$ was $4.1-4.5 \%$ among pregnant Hungarian women. Our data confirmed that higher maternal age is a key risk factor in $\mathrm{CH}$ because $\mathrm{CH}$ occurred more frequently in mothers over 30 years of age. $\mathrm{CH}$ was found more frequently in more educated females, which may explain the higher rate of folic acid and multivitamin supplementation among these women. The higher occurrence of migraine and cardiac dysrhythmias seems to be characteristic of mothers with $\mathrm{CH}$, but a higher risk of cardiovascular diseases, such as coronary artery disease and renal disease, was not observed among these pregnant women (mean age, about 26 years).

The initiation of antihypertensive-drug therapy is usually considered in pregnant women, if systolic blood pressure exceeds $159 \mathrm{~mm}$ $\mathrm{Hg}$ or diastolic pressure exceeds $109 \mathrm{~mm} \mathrm{Hg} .^{20-22}$ Pregnant women with Stage 1 hypertension, that is, with a low risk of $\mathrm{CH}$, should not be treated with drugs, but rather with dietary modification, particularly sodium reduction and more intensive physical activity. Notably, control of maternal weight gain was sufficient. ${ }^{3}$ Thus, we decided that pregnant women with untreated $\mathrm{CH}$ should be classified as stage 1. However, about $96 \%$ of our pregnant women were treated with antihypertensive drugs and were therefore considered as stage 2 .

A higher risk for multiple CAs was also found among the offspring of mothers who experienced severe, treated $\mathrm{CH}$ and related drug treatments. However, two cases with multiple malformations were identified as oligohydramnios sequences, due to renal defects; these two pregnant women were treated with captopril. Angiotensinconverting enzyme inhibitors ${ }^{23-25}$ and angiotensin-II receptor inhibitors/antagonists ${ }^{26,27}$ are contraindicated in pregnant women because of their fetotoxic effects (mainly renal failure). Captopril is an angiotensin-converting enzyme inhibitor (and therefore contraindicated in pregnant women); nevertheless, 10 pregnant women with $\mathrm{CH}$ were treated with captopril during pregnancy, and this drug was 
associated with the oligohydramnios sequence in two multimalformed offspring. There were two other cases with postural deformity association $^{28}$ born to mothers treated with prazosine. The possible human teratogenic potential of prazosine was not tested, but the results of an animal experiment have been published. ${ }^{29}$ Prazosine did not induce CAs, but intrauterine fetal growth retardation was found. The two cases investigated in this study exhibited similar results, and their lower birth weight was associated with postural deformity association. Thus, the possible human teratogenic/fetotoxic effect of prazosine requires further investigation. In conclusion, the higher risk of multiple CAs in the offspring of pregnant women with $\mathrm{CH}$ may be associated with the fetotoxic effect of captopril and prazosine used for the treatment of $\mathrm{CH}$.

However, the three-fold increase in the risk of esophageal atresia/ stenosis requires an explanation The question is whether this association is caused by $\mathrm{CH}$; can be explained by related drug treatments, other diseases, lifestyle factors and other or unevaluated confounders; or occurs by chance.

To identify a possible causal association, we have to consider the possible maternal teratogenic effect of $\mathrm{CH}$. A previous study ${ }^{30}$ included 29 pregnant women with severe hypertension (diastolic pressure exceeded $110 \mathrm{~mm} \mathrm{Hg}$ in all women), all of whom were treated with intravenous magnesium sulfate and other antihypertensive drugs. Beyond the intrauterine growth retardation, higher risks of microcephaly, patent ductus arteriosus and hypotonia of the skeletal and gut musculature were found. In a recent study by Caton et al., 31 the possible association of maternal hypertension with antihypertensive-drug treatment and CA was evaluated, and a higher risk of hypospadias was found. This finding was not confirmed in our study. Hyperthyroidism requires special attention because antithyroid drugs such as methimazole/carbimazole may cause esophageal atresia/ stenosis. ${ }^{32,33}$ However, among the 21 cases with esophageal atresia/ stenosis, only one had a mother with $\mathrm{CH}$ and hyperthyroidism, and this woman was not treated with antithyroid drugs. In addition, our previous study showed an association of $\mathrm{CH}$ with hyperthyroidism in pregnant women, and hyperthyroidism without antithyroid treatment also showed some association with a higher risk for esophageal atresia/ stenosis. ${ }^{34}$ The association of other maternal diseases with higher risk of CAs was studied in two other investigations, ${ }^{35,36}$ but an association of $\mathrm{CH}$ with esophageal atresia/stenosis was not reported.

The birth prevalence of cases with isolated esophageal atresia/ stenosis with or without tracheo-esophageal fistula is 0.18 per 1000 in Hungary; this figure is similar in other countries. ${ }^{37}$ The epidemiological characteristics of esophageal atresia/stenosis with or without tracheo-esophageal fistula are well known, ${ }^{38-41}$ but 21 cases born to mothers with $\mathrm{CH}$ in the study did not fit the associations found previously (for example, younger age and lower employment status). The etiology of esophageal atresia/stenosis is not well understood. ${ }^{41,42}$ Obviously, both genetic and environmental factors have a role in the origin of esophageal atresia/stenosis \pm tracheo-esophageal fistula; ${ }^{42,43}$ among environmental factors, maternal exposure to cigarette smoking and alcohol during early pregnancy is important. ${ }^{44,45}$ The mothers with CAs of both cases (29.7 vs. 21.6\%) and controls (22.2 vs. 18.5\%), smoked more frequently during pregnancy than case and control mothers without $\mathrm{CH}$. Thus, smoking may be a factor that triggers the genetic pre-disposition to esophageal atresia/stenosis.

The muscular layer of arteries is a target tissue in $\mathrm{CH}$ with multifactorial etiology. The consequences of a polygenic-environmental interaction $^{1,2}$ and maldevelopment of the muscular system may also have a role in the pathogenesis of esophageal atresia/stenosis. Thus, our hypothesis is that esophageal atresia/stenosis and $\mathrm{CH}$ may share a common genetic predisposition; however, further studies are needed to confirm or reject this hypothesis.

At the decision to proceed with antihypertensive therapy, drugs must be chosen on the basis of considerations specific to the pregnancy, mainly with regard to the health of the fetus. In general, if drug therapy is necessary in pregnant women, methyldopa is the first choice because its safety has been shown in several studies. ${ }^{46-48}$ However, this recommendation was not followed in Hungarian pregnant women with $\mathrm{CH}$; methyldopa was only the fourth and fifth most frequently used drug in case and control mothers, respectively. Direct vasodilators, such as hydralazine and beta-receptor blockers, were also found to be effective and safe. ${ }^{47,48}$ Our previous study did not indicate any teratogenic and/or fetotoxic effects of calcium receptor antagonists. ${ }^{49}$ Aside from the above drugs, terbutaline and fenoterol were used in more than $10 \%$ of pregnant women; the limited human data available did not indicate any teratogenic effects. ${ }^{48}$ Thus, our study did not show any association between $\mathrm{CH}$ related drug treatment and esophageal atresia/stenosis. In addition, it is worth stressing that antihypertensive drugs-beyond angiotensinconverting enzyme inhibitors and angiotensin-II receptor inhibitors/ antagonists, in addition to perhaps prazosine-are safe. Furthermore, pregnant women with $\mathrm{CH}$ also require treatment during pregnancy. ${ }^{12}$

Another possible explanation for this association is unevaluated/ unknown confounders. Finally, multiple comparisons may produce non-causal associations because a significant difference is expected at every 20th estimation due to chance.

The three-fold higher relative risk for isolated esophageal atresia/ stenosis in the children of pregnant women with $\mathrm{CH}$, seems to be important; however, we have to consider that about $4-5 \%$ of pregnant women have $\mathrm{CH}$. If one assumes 100000 births per year, 4500 pregnant women with $\mathrm{CH}$, and a three-fold increase in the expected rate of esophageal atresia/stenosis, 2.7 cases rather than 0.9 cases are expected each year. This increase of about two cases is interesting from an academic perspective, but is not clinically important.

The advantages of the HCCSCA data set are that it is a large population-based data set, including 2627 pregnant women with prospectively and medically recorded $\mathrm{CH}$ from among an ethnically homogeneous European (Caucasian) population. We were able to differentiate the different groups of hypertension among the study pregnancies, and we evaluated only $\mathrm{CH}$ because our objective was to evaluate a homogeneous sample. Additional advantages are the matching of cases to controls without CAs, data related to potential confounders, and the diagnosis of medically reported CAs as confirmed in the HCAR. ${ }^{13}$ The diagnosis was later modified, if necessary, on the basis of recent medical examination within the HCCSCA. $^{12}$

However, this data set also has limitations. (i) The severity of $\mathrm{CH}$ was not based on the changing blood pressure values, but only on related drug treatments. (ii) We did not know any details regarding the onset of $\mathrm{CH}$ before the study pregnancy. (iii) Systolic and diastolic blood pressure could not be evaluated separately in this populationbased study. (iv) Other pregnancy outcomes, for example, miscarriages, were not known; the rate of low birth weight (including intrauterine fetal growth retardation) and preterm birth were evaluated in another study. ${ }^{12}$ (v) Nearly all treated pregnant women with $\mathrm{CH}$ had previously undergone polytherapy; therefore, we were not able to differentiate the effect of each drug. Related drug treatment did not modify the association of $\mathrm{CH}$ and isolated $\mathrm{CA}$, which was shown only in cases with multiple CAs. (vi) Lifestyle factors could not be evaluated in the total data set because of the unreliability of selfreported maternal data. ${ }^{50}$ 
In conclusion, severe $\mathrm{CH}$ in pregnant women may be associated with a higher risk of esophageal atresia/stenosis in their offspring. This finding requires further research because $\mathrm{CH}$ is one of the most common pathological conditions among pregnant women.

\section{CONFLICT OF INTEREST}

The authors declare no conflict of interest.

1 Pickering TG, Ogedegbe G. Epidemiology of hypertension. In: Fuster V, Walsh RA, O'Rourke RA, Poole-Wilson P (eds). Hurst's The Heart, 12th edn. McGraw Hill Medical: New York, 2008, pp 1551-1569.

2 Hall JE, Granger JP, Hall ME, Jones DW. Pathophysiology of hypertension. Fuster V, Walsh RA, O'Rourke RA, Poole-Wilson P (eds). Hurst's The Heart, 12th edn. McGraw Hill Medical: New York, 2008, pp 1570-1609.

3 Rashidi A, Rachman M, Wright JT. Diagnosis and treatment of hypertension. In: Fuster V, Walsh RA, O'Rourke RA, Poole-Wilson P (eds). Hurst's The Heart, 12th edn. McGraw Hill Medical: New York, 2008, pp 1610-1629.

4 Rey E, LeLorier J, Burgess E, Lange IR, Leduc L. Report of the Canadian Hypertension Society Consensus Conference. 3. Pharmacologic treatment of hypertensive treatment in pregnancy. Can Med Assoc J 1997; 157: 1245-1254.

5 Gifford R, August P, Cunningham G. Report of the National High Blood Pressure Education Program Working Group on High Blood Pressure in Pregnancy. Am J Obstet Gynecol 2000; 183: S1-S15.

6 Churchill D. The new American guidelines on the hypertensive disorders of pregnancy. $J$ Hum Hypertens 2001; 15: 583-585.

7 Chobanian AV, Bakris GL, Black HR, Cushma WC, Green LA, Izzo Jr JL, Jones DW Materson BJ, Oparil S, Wright Jr JT, Roccella EJ, National Heart, Lung, and Blood Institute Joint National Committee on Prevention, Detection, Evaluation, and Treatment of High Blood Pressure; National High Blood Pressure Education Program Coordinating Committee. The seventh report of the Joint National Committee on Prevention, Detection, Evaluation and Treatment of High Blood Pressure: the JNC 7 report. JAMA 2003; 289: 2560-2572.

8 JNC 7. The seventh report of the Joint National Committee on Prevention, Detection, Evaluation and Treatment of High Blood Pressure (JNC 7): the guidelines. Hypertens 2003; 42: 1206-1210.

9 Roberts JM. Pregnancy-related hypertension. In: Creasy RK, Resnik R, lams JD (eds). Maternal-Fetal Medicine. Principles and Practice, 5th edn. Saunders: Philadelphia, 2004, pp 859-899.

10 Abalos E, Duley L, Steyn DW, Henderson-Smart DJ. Antihypertensive drug therapy for mild to moderate hypertension during pregnancy. Cochrane Databases Syst Rev 2007 1: CD002252.

11 McAnulty JH, Brober CS, Metcalfe J. Heart disease and pregnancy. In: Fuster V, Walsh RA, O'Rourke RA, Poole-Wilson P (eds). Hurst's The Heart, 12th edn McGraw Hill Medical: New York, 2008, pp 2188-2202.

12 Bánhidy F, Ács N, Puho HE, Czeizel AE. The efficacy of antihypertensive treatment in pregnant women with chronic and gestational hypertension: a population-based study. Hypertens Res 2010; 33: 460-466.

13 Czeizel AE, Rockenbauer M, Siffel C, Varga E. Description and mission evaluation of the Hungarian Case-Control Surveillance of Congenital Abnormalities, 1980-1996. Teratology 2001; 63: 176-185.

14 Czeizel AE. The first 25 years of the Hungarian Congenital Abnormality Registry. Teratology 1997; 55: 299-305.

15 Czeizel AE, Intödy Z, Modell B. What proportion of congenital abnormalities can be prevented? Brit Med J 1993; 306: 499-503.

16 Czeizel AE, Petik D, Vargha P. Validation studies of drug exposures in pregnant women. Pharmacoepid Drug Safety 2003; 2: 409-416.

17 Czeizel AE, Vargha P. Periconceptional folic acid/multivitamin supplementation and twin pregnancy. Am J Obstet Gyencol 2004; 191: 790-794.

18 Puho E, Métneki J, Czeizel AE. Maternal employment status and isolated orofacial clefts in Hungary. Cent Eur J Publ Health 2005; 13: 144-148.

19 Czeizel AE. Pedriconceptional folic acid and multivitamin supplementation for the prevention of neural tube defects and other congenital abnormalities. Birth Defects Res (Part A) 2009; 85: 260-268.

20 Roberts JM, Perloff DL. Hypertension and the obstetrician-gynecologist. Am J Obstet Gynecol 1997; 127: 316-322.

21 Arias F, Zamora J. Antihypertensive treatment and pregnancy outcome in patients with mild chronic hypertension. Obstet Gynecol 1979; 53: 489-492.

22 Sibai BM. Chronic hypertension in pregnancy. Obstet Gynecol 2002; 100: 369-377.
23 Hanssens M, Keirse MJNC, Vankelecom F, Van Assche FA. Fetal and neonatal effects of treatment with angiotensin converting enzyme inhibitors in pregnancy. Obstet Gynecol 1991; 78: 128-135.

24 Burrows RF, Burrows EA. Assessing the teratogenic potential of angiotensin-converting enzyme inhibitors in pregnancy. Aust N Z Obstet Gynaecol 1998; 38: 306-311.

25 Cooper WD, Hernandez-Diaz S, Arbogast PQ, Dudley JA, Dyer S, Gideon PS, Hall K, Ray WA. Major congenital malformations after first-trimester exposure to ACE inhibitors. N Engl J Med 2006; 354: 2443-2451.

26 Lambot MA, Vermeylen D, Noel JC. Angiotensin-II-receptor inhibitors in pregnancy. Lancet 2001; 357: 1619-1620.

27 Martinovic J, Benachi A, Laurent N, Daikha-Dahmane F, Gubler MC. Fetal toxic effects and angiotensin-II-receptor antagonists. Lancet 2001; 358: 241.

28 Pazonyi I, Bod M, Czeizel AE. Postural association. Acta Paediatr Acad Sci Hung 1983; 23: 431-445.

29 Noguchi Y, Ohwaki Y. Reproductive and teratologic studies with prazosin hydrochloride in rats and rabbits. Oyo Yakuri 1979; 17: 57-62.

30 Brazy JE, Grimm JK, Little VA. Neonatal manifestations pf severe maternal hypertension occurring before the thirty-sixth week of pregnancy. J Pediatr 1982; 100: 265-271.

31 Caton AR, Bell EM, Druschel CM, Werler MM, Mitchell AA, Browne ML, McNutt LA, Romitti PA, Olney RS, Correa A, National Birth Defects Prevention Study. Maternal hypertension, antihypertensive medication use, and the risk of severe hypospadias. Birth Defects Res (Part A) 2008; 82: 34-40.

32 Ramirez A, de los Monteros A, Parra A, De Leon B. Esophageal atresia and tracheoesophageal fistula in two infants born to hyperthyroid women receiving methimazole (Tapazol $^{\mathrm{TM}}$ ) during pregnancy. Am J Med Genet 1992; 44: 200-202.

33 Diav-Citrin 0, Ornoy A. Teratogen Update: Antithyroid drugs-methimazole, carbimazole and propylthiouracil. Teratology 2002; 65: 38-44.

34 Bánhidy F, Puho HE, Czeizel AE. Possible association between hyperthyroidism in pregnant women and obstructive congenital abnormalities of urinary tract in their offspring - a population-based case-control study. J Mat-Fetal Neonat Med 2010 (e-pub ahead of print 26 May 2010: PMID: 20504076).

35 Ordonez MP, Nazer J, Aguila A, Cifuentes L. Association between congenital malformations and chronic disease of the mother. Rev Medica Chile 2003; 131: 404-411.

36 Van Landingham M, Nguyen TV, Roberts A, Parent AD, Zhang J. Risk factors of congenital hydrocephalus: a 10 year retrospective study. I Neurol Neurosurg Psychiatr 2009; 80: 213-217.

37 Czeizel $A E$, Vitéz $M$. Birth prevalence of five congenital abnormalities of medium frequency in Budapest. Acta Paediat Acad Sci Hung 1981; 22: 199-308.

38 Depaepe A, Dolk H, Lechat M. The epidemiology of tracheo-oesophageal fistula and oesophageal atresia in Europe. Arc Dish Child 1993; 68: 743-748.

39 Robert E, Mutchinik O, Mastroiacovo P, Knudsen LB, Daltveit AK, Castilla EE, Lancaster P, Källén B, Cocchi G. An international collaborative study of the epidemiology of esophageal atresia or stenosis. Reprod Toxicol 1993; 7: 405-421.

40 Torfs CP, Curry CJ, Bateson TF. Population-based study of tracheoesophageal fistula and esophageal atresia. Teratology 1995; 52: 220-232.

41 Szendrey T, Danyi G, Czeizel AE. Etiological study on isolated esophageal atresia. Hum Genet 1985; 70: 51-58.

42 Felix JF, van Dooren MF, Klaassens M, Hop WC, Torfs CP, Tibboel D. Environmental factors in the etiology of esophageal atresia and congenital diaphragmatic hernia: results of a case-control study. Birth Defects Res (Part A) 2008; 82: 98-105.

43 Felix JF, de Jong EM, Torfs CP, de Klein A, Rottier RJ, Tibboel D. Genetic and environmental factors in the etiology of esophageal atresia and/or tracheoesophageal fistula: An overview of the current concepts. Birth Defects Res (Part A) 2009; 85: 111-116.

44 Wong-Gibbons DL, Romitti PA, Sun L, Moore CA, Reefhuis J, Bell EM, Olshan AF. Maternal periconceptional exposure to cigarette smoking and alcohol and esophageal atresia \pm tracheoesophageal fistula. Birth Defects Res (Part A) 2008; 82: 776-784.

45 Oddsberg J, Jia C, Nilsson E, Ye W, Lagergren J. Maternal tobacco smoking, obesity, and low socioeconomic status during early pregnancy in the etiology of esophageal atresia. J Pediat Surg 2008; 43: 1791-1795.

46 Ounsted M, Cockburn J, Moar VA, Redman CW. Maternal hypertension with superimposed preeclampsia: Effects on child development at 71frac2; years. $\mathrm{Br} \mathrm{J}$ Obstet Gynecol 1983; 90: 644-650.

47 Shepard TH, Lemire RJ. Catalog of Teratogenic Agents, 11th edn. Johns Hopkins Univ Press: Baltimore, 2004.

48 Briggs GG, Freeman RK, Yaffe SJ. Drugs in Pregnancy and Lactation, 7th edn. Lippincot Williams and Wilkins: Philadelphia, 2005.

49 Sorensen HT, Czeizel AE, Rockenbauer M, Steffensen FH, Olsen J. The risk of limb deficiencies and other congenital abnormalities in children exposed in utero to calcium channel blockers. Acta Obstet Gynaecol Scand 2001; 80: 379-401.

50 Czeizel AE, Petik D, Vargha P. Smoking and alcohol drinking during pregnancy. The reliability of retrospective maternal self-reported information. Cent Eur J Publ Health 2004; 12: 179-183. 